\title{
Analysis of amplitude and travel-time anomalies for short-period $P$-waves from NTS explosions
}

\author{
Christopher S. Lynnes and Thorne Lay \\ Department of Geological Sciences, University of Michigan, Ann Arbor, MI 48109, USA
}

Accepted 1987 August 19. Received 1987 March 2; in original form 1986 December 3

\begin{abstract}
SUMMARY
Short-period $P$-wave amplitudes from explosions at the Nevada Test Site (NTS) have strong, slowly varying azimuthal patterns, which may result from receiver effects, tectonic release interference, attenuation differences or near-source heterogeneity. In order to determine which factor is responsible for the non-isotropic radiation patterns, $m_{\mathrm{b}}$ and travel-time anomalies have been measured for 57 explosions at the Pahute Mesa and Yucca Flat sub-sites, as well as the Central Nevada explosion FAULTLESS, using teleseismic WWSSN and Canadian Seismograph Network stations. Magnitude anomalies from 12 earthquakes in the western United States have also been determined to characterize the near-receiver effects. Stations north to northeast of NTS record amplitudes that are a factor of 2.5 lower than those to the southeast and west for Pahute Mesa events and a factor of 1.7 lower for Yucca Flat events. Stations to the northeast of NTS also record travel times that are $1.4 \mathrm{~s}$ faster than those to the northwest and southeast for Pahute Mesa tests, and $1 \mathrm{~s}$ faster for Yucca Flat tests. The $m_{\mathrm{b}}$ and travel-time anomalies are positively correlated for the NTS explosions, suggesting the predominance of elastic focusing and defocusing, rather than attenuation or tectonic release effects. Applying the regional event $m_{\mathrm{b}}$ values as receiver corrections leaves a small common component in the NTS $m_{\mathrm{b}}$ patterns, which must be produced by velocity heterogeneity deep enough $(>200 \mathrm{~km})$ to affect both Pahute Mesa and Yucca Flat events. However, the principal long-wavelength variation in the receiver-corrected magnitudes is unique to Pahute Mesa. The travel-time patterns for the two NTS sub-sites are quite similar and have a systematic counter-clockwise rotation from the FAULTLESS travel-time pattern, indicating that a deep $(>400 \mathrm{~km})$ high-velocity anomaly is responsible for the strong common component of the travel-time variations. The spatially varying components of the $m_{\mathrm{b}}$ and travel-time patterns between NTS sub-sites are isolated by subtracting the station average $m_{\mathrm{b}}$ and travel-time anomalies for Yucca Flat from those for Pahute Mesa. The intersite differences have smooth azimuthal variations, with a positive correlation between differenced $m_{\mathrm{b}}$ and travel-time anomalies. This suggests that focusing and defocusing by near-source velocity heterogeneity, most of which is probably concentrated in a high-velocity body in the crust and upper mantle ( $<200 \mathrm{~km}$ deep) northeast of Pahute Mesa, causes the strong intersite amplitude variations.
\end{abstract}

Key words: amplitudes, Nevada Test Site, $P$-waves, travel times

\section{INTROD UCTION}

The theoretically isotropic radiation pattern and wellconstrained hypocentral parameters of underground explosions have made them the preferred sources for the study of short-period wave propagation. Yet many aspects of seismic signals from explosions remain unexplained. One such anomaly is the strong azimuthal variation in short-period $P$-wave amplitudes from underground explosions at the Pahute Mesa test site in Nevada (Lay et al. 1984). Lay et al. (1984) explored the possibility that this variation results from interference with tectonic release radiation. However, the amplitude pattern could also be produced by velocity or attenuation heterogeneity near the source or along the ray-paths, or by systematic receiver variations. The motivation for this study is to determine which of these effects is responsible for the amplitude pattern observed for these events.

The various possible explanations have profound implications for treating $m_{\mathrm{b}}$ bias in yield estimation. For instance, bias due to tectonic release interference might be taken into account by using $S H$-waves to estimate the tectonic release radiation, whereas bias due to systematic receiver effects could be removed using empirical receiver corrections. On the other hand, the effect of near-source heterogeneity is site-specific and may introduce significant and unrecognized bias into $m_{\mathrm{b}}$ determinations based on a limited station 
distribution or a single array such as the Norwegian Seismic Array (NORSAR).

The near-source velocity heterogeneity itself is also of interest. In fact, the dense, well-located array of sources at the Nevada Test Site (NTS) offers an excellent opportunity to image upper-mantle heterogeneity in a geologically interesting area using both amplitudes and travel times. Finally, by isolating the contributions of the various sources of non-isotropic radiation, we should be able to ascertain whether a deterministic, rather than stochastic, approach to short-period wave propagation through the mantle is viable for frequencies around $1 \mathrm{~Hz}$.

The azimuthal pattern found by Lay et al. (1984) was detected in short-period $a b$ (first peak-to-first trough) amplitudes recorded at teleseismic WWSSN and Canadian Seismograph Network (CSN) stations. Low amplitudes were observed at stations to the NNE and high amplitudes at stations to the $\mathrm{W}, \mathrm{E}$ and $\mathrm{SE}$. The long-wavelength (i.e. slowly-varying) component of the azimuthal trend is well-parameterized as a $\sin 2 \theta$ curve, leading to the hypothesis that it results from the superposition of a vertical strike-slip tectonic release component believed to be appropriate for Pahute Mesa explosions (Wallace et al. 1983,1984 ) and the isotropic component (Lay et al. 1984). However, the authors also pointed out that extremely high stress drops and nearly simultaneous triggering of the tectonic release are required to produce significant interference in the first cycle of the waveforms, and all of the Pahute Mesa events must be similarly affected. Tectonic release interference is not expected to have an effect on the travel times of short-period $P$-waves.

On the other hand, several studies of explosion $P$-waves have resolved lateral velocity heterogeneity in the crust and upper mantle beneath Pahute Mesa. Spence (1974) studied travel time anomalies for Pahute Mesa explosions relative to the Yucca Flat test DUMONT and found stations from $60^{\circ}$ to $90^{\circ}$ away to be about $1 \mathrm{~s}$ fast. He attributed this to propagation through a high-velocity upper mantle root of the Silent Canyon caldera, which encompasses Pahute Mesa. Minster et al. (1981) and Taylor (1983) performed block inversions of teleseismic $P$-wave travel times for Pahute Mesa and Yucca Flat explosions that yielded models with high velocities in the lithosphere to the NE below Pahute Mesa. The combined studies indicate a general correspondence between low amplitudes and fast travel times toward the NE, which suggests an elastic focusing/defocusing effect rather than tectonic release interference.

Variations in $P$-wave amplitudes resulting from nearsource effects have been. demonstrated for other source regions, such as the Novaya Zemlya test site (Butler \& Ruff 1980; Burger et al. 1986). Near-source signatures have also

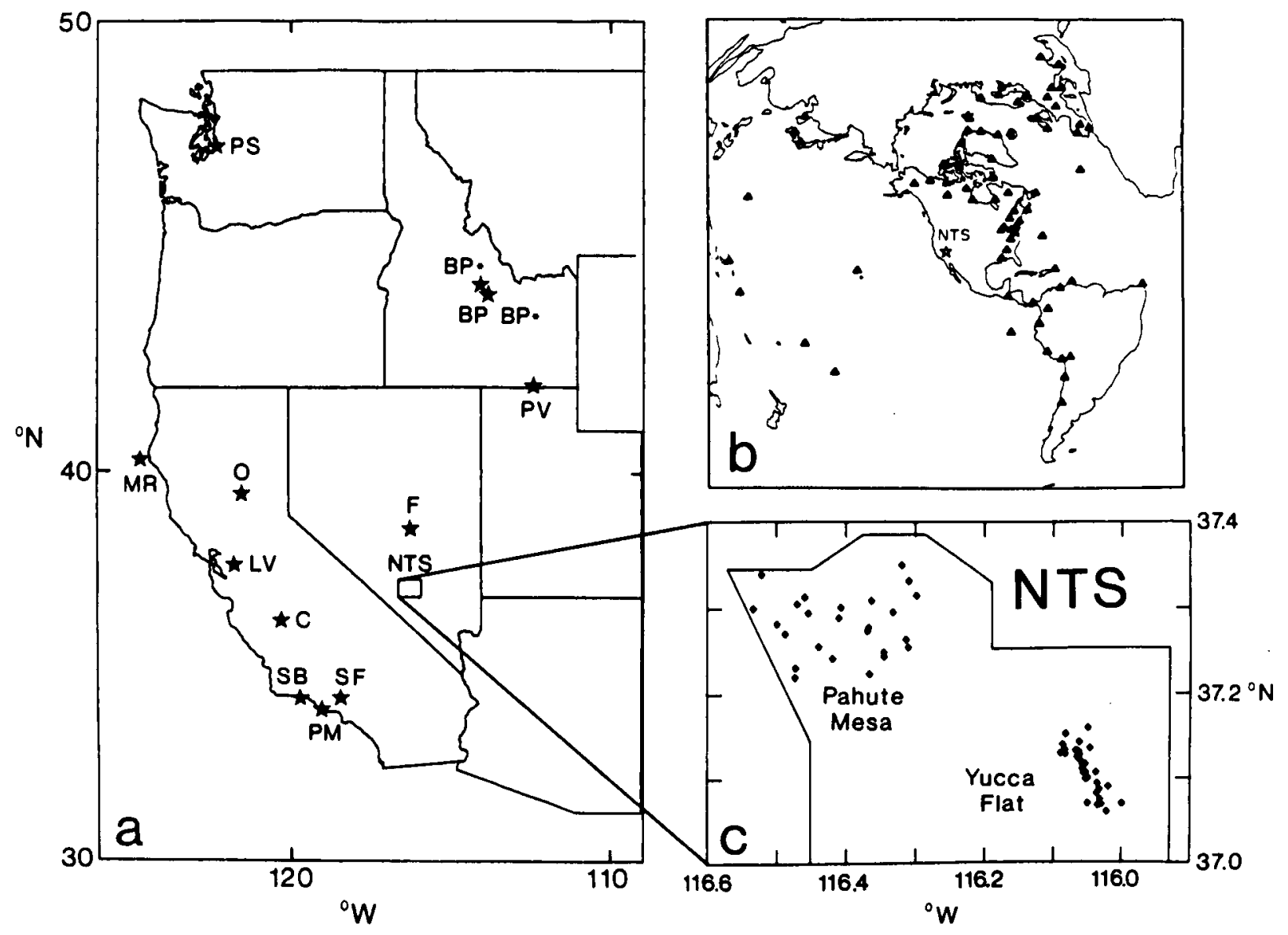

Figure 1. (a) Base map showing the locations of the Nevada Test Site (NTS), FAULTLESS (F) and the regional earthquakes (stars) used to identify the near-receiver component of the magnitude anomalies. Each event is identified by its initial(s) (see Table 1). (b) Distribution of the 71 teleseismic WWSSN and CSN stations used in this study, plotted on an azimuthal equal-distance projection centred on NTS. (c) Base map of NTS showing the 25 Pahute Mesa and 32 Yucca Flat explosions used in this study. 
been found in earthquake travel-time data, most notably for deep slabs (e.g. Creager \& Jordan 1984). These near-source effects are generally identified on the basis of slowly-varying patterns with respect to take-off angle and azimuth from the source.

A number of observational studies have addressed the relationship between travel-time and amplitude variations in terms of elastic focusing/defocusing by upper-mantle lateral velocity heterogeneity. Several authors (e.g. Davies \& Julian 1972; Sleep 1973) have attempted to identify the shadow zone for high-velocity slabs using teleseismic $P$-wave amplitude or magnitude variations. Amplitude modulation by near-receiver heterogeneity has been invoked to explain positive correlations of late travel times with enhanced amplitudes at the Large Aperture Seismic Array (LASA) in Montana by Aki (1973) and Chang \& von Seggern (1980). Several studies have linked amplitude and travel-time anomalies at NORSAR by hypothesizing lateral velocity variations in the crust and/or upper mantle, with fast travel times usually correlating with low amplitudes (Haddon \& Husebye 1978; Thomson \& Gubbins 1982; Thomson 1983). In contrast, models hypothesizing variations in anelastic parameters usually predict a correlation of slow travel times with low amplitudes (cf. Butler 1984).

In this study, we attempt to determine the contribution of near-source velocity heterogeneity to the azimuthal variation of short-period $P$-wave radiation from underground explosions at NTS. This determination is based on a joint analysis of magnitude and travel-time anomalies measured from the same signals for the NTS test sites Pahute Mesa and Yucca Flat, and for the explosion FAULTLESS in central Nevada. Magnitude anomalies for several earthquakes in the western United States (Fig. 1) were also collected and analysed to characterize nearreceiver effects.

\section{METHOD OF STUDY}

We have adopted a data-intensive approach involving comparisons of amplitude and travel-time patterns for a variety of source regions in order to ascertain how much of the variation results from near-source effects. We supplement the amplitude measurements (converted to magnitudes) for the 25 Pahute Mesa events of Lay et al. (1984) with $m_{\mathrm{b}}$ determinations for 32 explosions at the Yucca Flat sub-site, for FAULTLESS in central Nevada $(150 \mathrm{~km}$ north of NTS), and for 12 earthquakes in the western United States (Fig. 1, Table 1), at the same 71 WWSSN and CSN stations (Fig. 1) used by Lay et al. (1984). To address the possibility that the near-source variation is due to tectonic release contamination, we have also measured the travel times for the same source-station pairs for all the explosions mentioned above. A total of 2599 magnitudes and 2107 travel times were uniformly measured.

Although reliable azimuthally-dependent station corrections for travel times have been determined for most of the stations used in this study (Dziewonski \& Anderson 1983), corresponding reliable amplitude corrections are not available, necessitating the inclusion of the regional earthquake magnitude data to identify and remove near-receiver magnitude effects. Several studies have
Table 1. Regional event data set.

\begin{tabular}{|c|c|c|c|c|c|c|c|c|}
\hline Event & Date & Time & $\begin{array}{l}\text { Lat. } \\
\left({ }^{\mathbf{0}} \mathbf{N}\right)\end{array}$ & $\begin{array}{l}\text { Long. } \\
\left({ }^{\circ} W\right)\end{array}$ & Str. & Dip & Slip & Ref. \\
\hline Borah Peak & $10-28-83$ & 14:06:07 & 44.10 & 113.81 & 304 & 29 & -103 & 1 \\
\hline Borah Peak • & $10-28-83$ & 19:51:25 & 44.11 & 113.82 & 287 & 32 & -157 & 1 \\
\hline Borah Peak • & $10-29-83$ & $23: 29: 12$ & 44.33 & 114.05 & 296 & 39 & -122 & 1 \\
\hline Coalinga & $5-02-83$ & $23: 42: 38$ & 36.24 & $1: 0.27$ & 320 & 30 & 87 & 1 \\
\hline Livermore Valley & $1-24-80$ & 19:00:09 & 37.77 & 121.70 & 149 & 49 & -172 & 1 \\
\hline Mendocino Ridge & $8-24-83$ & 13:36:29 & 42.04 & 124.66 & 93 & 65 & 153 & 1 \\
\hline Oroville & $8-01-75$ & $20: 20: 14$ & 39.50 & 121,47 & 180 & 65 & -70 & 2 \\
\hline Pocateilo Valley & $3-28-75$ & $2: 31: 06$ & 42.04 & 112.41 & 1 & 60 & -116 & 3 \\
\hline Point Mugu & $2-21-73$ & $14: 45: 57$ & 34.07 & 119.04 & 249 & 49 & 70 & 4 \\
\hline Puget Sound & $4-29-65$ & $15: 28: 44$ & 47.41 & 122.29 & 344 & 70 & -75 & 5 \\
\hline San Fernando & $2-09-71$ & $14: 00: 41$ & 34.40 & 118.43 & 290 & 53 & 76 & 6 \\
\hline Santa Barbara & $8-13-78$ & $22: 54: 52$ & 34.40 & 119.66 & 295 & 30 & so & 7 \\
\hline aftershock & & & & & & & & \\
\hline
\end{tabular}

References: 1--Ekstrom \& Dziewonski (1985), 2--Langston \& Butler (1976), 3--Bache, Lambert \& Barker (1980), 4--Ellsworth et al., (1973), 5--Langston \& Blum (1977), 6--Langston (1978), 7--Wallace, Helmberger \& Ebel (i98i)

tabulated $m_{\mathrm{b}}$ biases for many of the stations used in this study (e.g. North 1977; Ringdal 1984), providing azimuthally-independent corrections. However, azimuthal amplitude variations at a given station or array have been shown to be substantial (Berteussen 1975; Chang \& von Seggern 1980; Butler 1984). The regional earthquake sources in this study were thus selected to provide station corrections with appropriate back-azimuths to NTS.

For the explosion $\boldsymbol{P}$-waves, the amplitude and period measurements were always made on the $a b$ half-cycle. The amplitude was corrected for the instrument gain at the measured period, divided by the period, and converted to $m_{\mathrm{b}}$ using the distance corrections of Veith \& Clawson (1972). The earthquakes were selected on the basis of size, focal mechanism, and waveform simplicity (Table 1). The amplitudes of short-period $P$-waves from earthquakes with ISC magnitudes less than $\mathbf{5 . 5}$ were generally too small to measure reliably. Also, only dip-slip and oblique-slip earthquakes were selected, in order to minimize radiation pattern effects.

As with the explosions, the $a b$ amplitudes were measured for the earthquake signals. For the more complicated waveforms, one or two additional cycles were measured in cases where station-to-station consistency could be assured. These measurements were averaged with the $a b$ results, after accounting for multiplicative factors (i.e. baseline shifts in $m_{\mathrm{b}}$ ) between the different cycles, to obtain a single value for a given seismogram. $P$-wave radiation corrections were calculated using the published focal mechanisms listed in Table 1. Measurements for stations that were close to $P$-wave radiation nodes for a given earthquake (theoretical amplitude less than 15 per cent of the maximum) were discarded, and the measurements for a given event were subdivided by azimuth so that the radiation corrections spanned no more than a factor of two within any group. Each group was then effectively treated as a separate source, further reducing bias from inaccurate focal mechanisms, directivity or multiple-source interference.

Since the data set was still somewhat sparse, measurements from FAULTLESS were incorporated into the regional reference set. Lay \& Welc (1987) showed that the 
logarithms of the rms values of the coda levels after $5 \mathrm{~s}$ into the $P$-wavetrain behave similarly to, but are less influenced by near-source effects than, $m_{\mathrm{b}}$ measurements for NTS explosions, so the FAULTLESS measurements used were for the logarithm of the rms amplitude in the interval from 5 to $15 \mathrm{~s}$ after the first arrival.

Once the explosion and earthquake magnitudes were collected, we employed a least-squares technique that solves for the relative source sizes $\left(f_{i}\right)$ to minimize the sum of the station scatter, $\phi^{2}$, (Ruff, 1985), i.e.,

$\phi^{2}=\sum_{i=1}^{N} \sum_{j=1}^{M} n_{j}\left[\left(x_{i j}+f_{i}-s_{j}\right) \delta_{i j}\right]^{2}$,

where $N$ is the number of events, $M$ the number of stations, $n_{j}$ the number of events recorded at the $j$ th station, $x_{i j}$ the $m_{\mathrm{b}}$ observation for the $i$ th event at the $j$ th station, $f_{i}$ the relative event (logarithmic) size factor to correct $x_{i j}, s_{j}$ the average of all the $m_{\mathrm{b}}$ anomalies at station $j$, and $\delta_{i j}$ is 1 if there is an observation for the $i$ th event at the $j$ th station and 0 if there is no observation.

The relative event sizes are used to adjust all the observations to a common source size. This technique was applied separately to the Pahute Mesa, Yucca Flat, and regional event (including FAULTLESS) data sets. Since the procedure adjusts the data relative to an arbitrary baseline, the data sets were also adjusted to zero mean, so that the anomalies reported here are variations from the data set average. Thus, the differences in event size have been removed so that we can focus our attention on the relative variations between observations for each data set.

The travel-time anomalies were computed by subtracting predicted travel times, with ellipticity and station corrections, from the observed times. The ellipticity corrections were calculated using the tables of Dziewonski \& Gilbert (1976). In order to remove receiver effects, we employed the azimuthally-dependent station corrections of Dziewsonki \& Anderson (1983). The theoretical travel times were calculated using Taylor's (1983) average velocity models for either Pahute Mesa or Yucca Flat in the crust, the T7 model (Burdick \& Helmberger 1978) in the upper mantle, and PREM (Dziewonski \& Anderson 1981) in the lower mantle. The model used for Pahute Mesa, although slower than Yucca Flat in the top $5 \mathrm{~km}$ due to the low-velocity caldera fill, is about $0.4 \mathrm{~s}$ faster averaged over the whole crust. These average crustal differences are well-constrained by $P_{n}$ sourcetime terms. It is important to note that the different reference crustal models used in calculating the theoretical times cannot be expected to produce azimuthal amplitude variations since they are laterally homogeneous within each sub-site. Instead, we seek azimuthal patterns in travel-time residuals that indicate lateral gradients departing from the reference structures.

Histograms of the absolute travel-time residuals are shown in Fig. 2 for each test site. The average residual for Pahute Mesa is $0.14 \mathrm{~s}$ larger than for Yucca Flat. (If a single reference structure, such as that of Hartzell et al. 1983, is used for both sites, the average Pahute Mesa residual is $0.3 \mathrm{~s}$ less than Yucca Flat.) Given the large variation in travel-time residuals, this difference is fairly small. It is also quite small relative to the variations in average event residuals, which vary by as much as $0.5 \mathrm{~s}$ within each
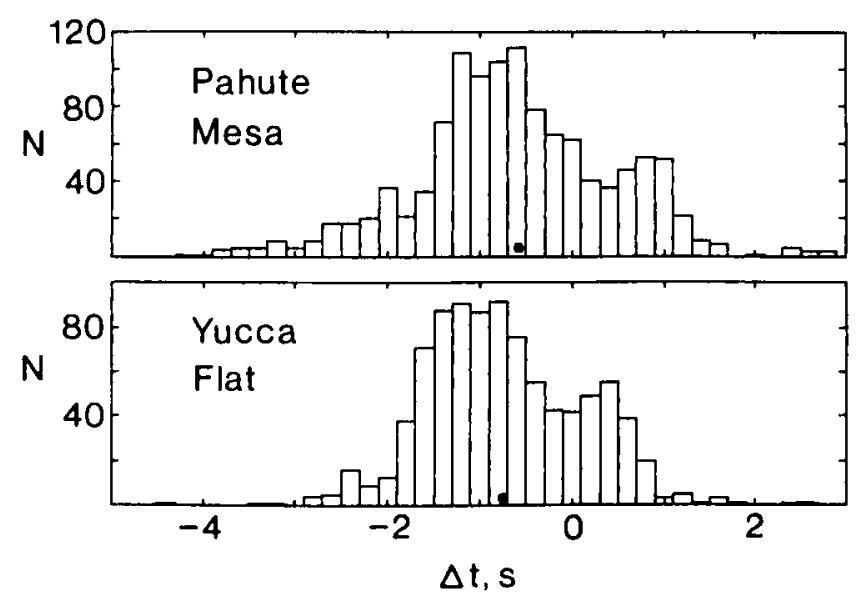

Figure 2. Histograms of travel-time residuals determined for Pahute Mesa (top) and Yucca Flat (bottom). The solid circles represent the means of each data set.

sub-site. These baseline variations may be due to differences in station distribution for each test, very shallow $(<5 \mathrm{~km})$ differences in structure, as well as uncertainties in the actual detonation times, which can occur as much as $0.4 \mathrm{~s}$ after the announced origin time. We did not observe systematic spatial variations in the average event residuals for Pahute Mesa, in agreement with Taylor's (1983) results, whereas there is some erratic E-W variation across Yucca Flat that could be removed using more localized structures. Since the azimuthal amplitude pattern found by Lay et al. (1984) is similar for all Pahute Mesa explosions, we are interested in whatever azimuthal travel-time pattern may also be common to all the events in a given site. Consequently, we have applied the least-squares analysis used with the $m_{\mathrm{b}}$ anomalies to the travel-time anomalies for Pahute Mesa and Yucca Flat separately. This absorbs into the adjustable source terms the intrasite differences in station distribution, very shallow structure and origin time bias. Also, in order to identify azimuthal travel-time patterns at each test site, both travel-time data sets were adjusted to zero mean, thus removing the $0.1 \mathrm{~s}$ baseline shift.

\section{AMPLITUDE AND TRAVEL-TIME DATA}

The final magnitude anomalies for the explosions and earthquakes are shown in Fig. 3, plotted for each station in order of azimuth from NTS, starting from north. The scatter for a given station is fairly small for the explosions, particularly compared to the variation between stations, reflecting the stability of the waveforms. The earthquakes, on the other hand, show somewhat greater scatter about the station means. This may be an effect of directivity, inconsistent picks due to waveform complexity, and/or inadequacy of the radiation correction for short-period $P$-waves. Additionally, each earthquake source region may contribute a different focusing/defocusing effect to the pattern. The two NTS data sets have some common characteristics in their overall patterns. Both sub-sites have low magnitudes at stations in northern Canada and northern Europe and high magnitudes at stations around the entire Pacific rim. The earthquake data set, on the other hand, does not have a similar systematic pattern. In fact, the 

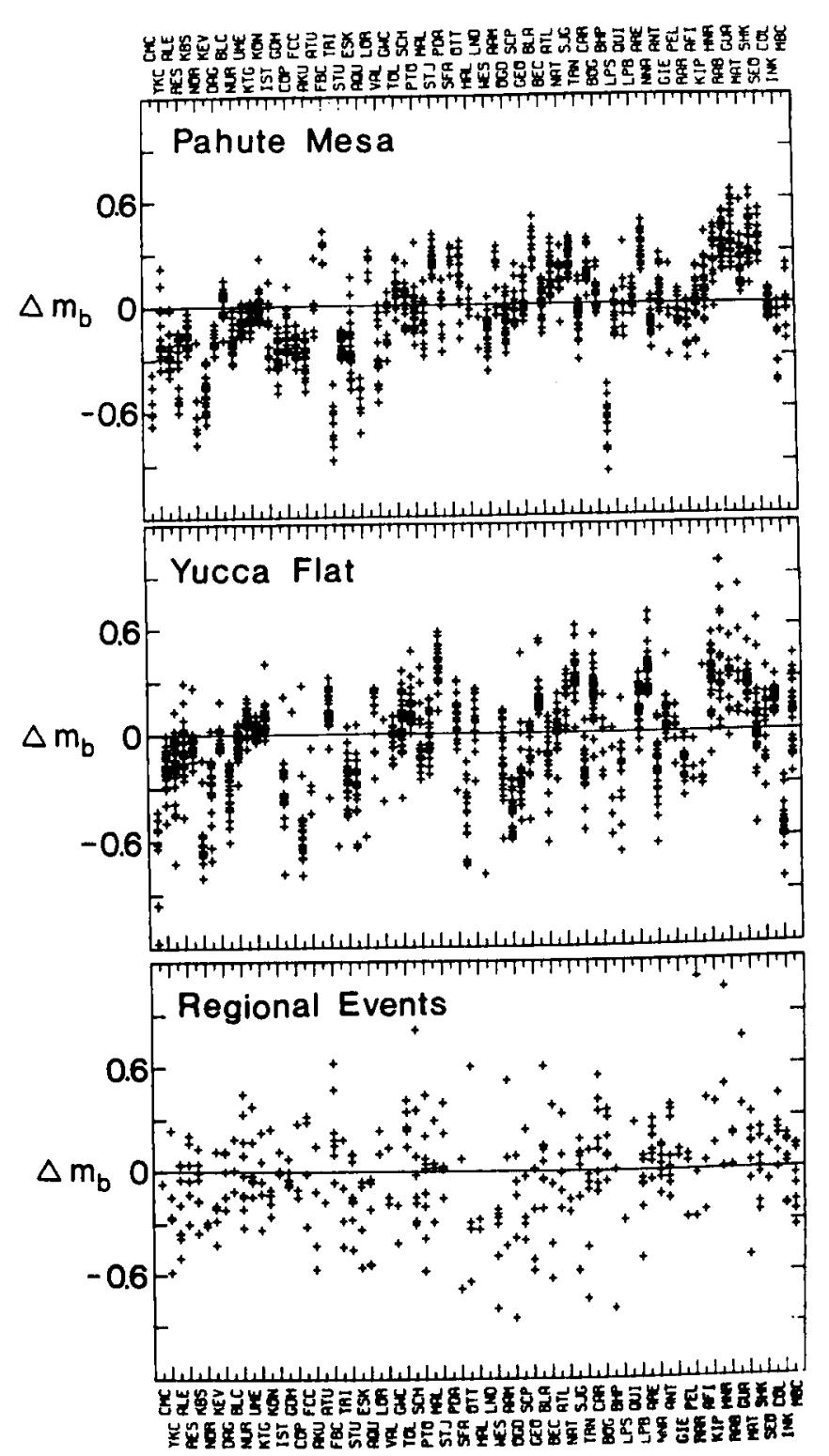

Figure 3. The complete data set of magnitude anomalies for Pahute Mesa (top), Yucca Flat (middle) and regional events (bottom), after adjustments for relative source size. The data are plotted by station in order of azimuth from NTS.

variance of the earthquake magnitude anomalies about the baseline is an order of magnitude less than the variances for the explosion data sets, despite the increased variance about the station means for the earthquakes. Therefore, the deviations in the explosion station means are not due primarily to near-receiver effects.

The travel-time anomalies for the NTS explosions are shown in Fig. 4. Once again, the scatter for the explosions at a given station is much less than the variation from station to station. Also, a strong systematic pattern with anomalies ranging over several seconds is visible, with fast times (negative anomalies) recorded in Europe and slow times in Central and South America. Thus, there is clearly some correspondence between fast times and low magnitudes, and between slow times and high magnitudes. The travel-time patterns for the two sub-sites are also quite similar to each

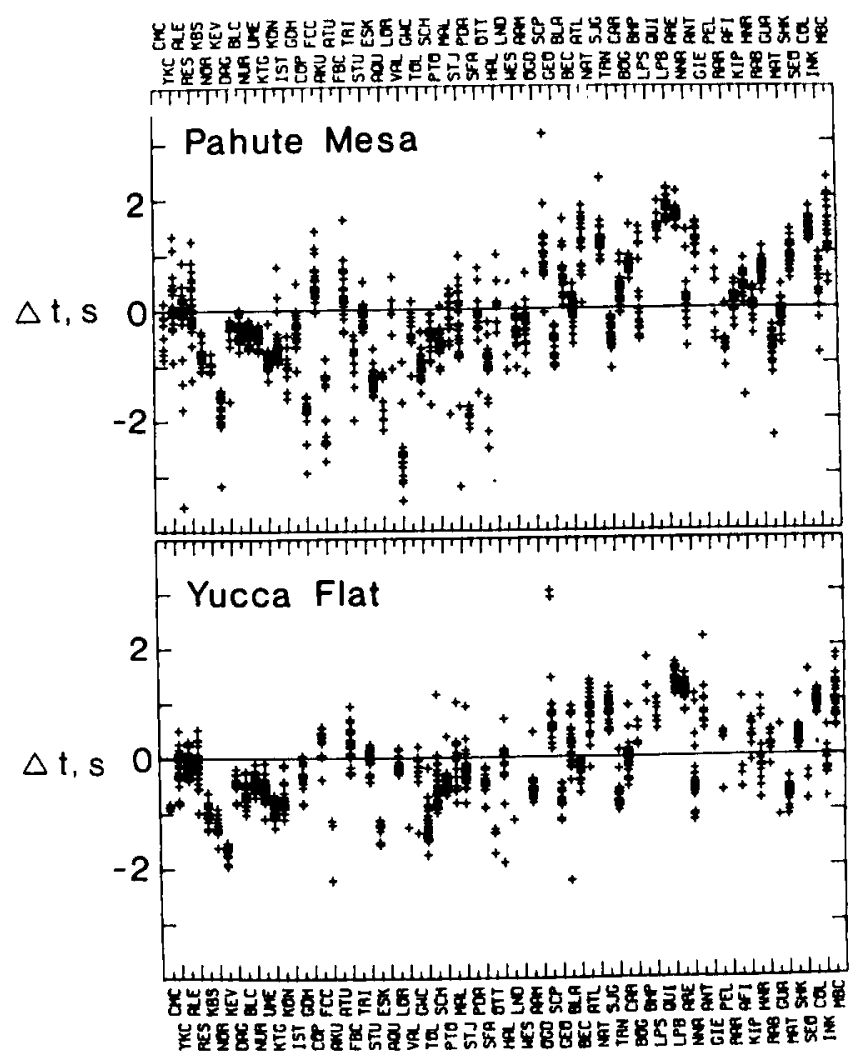

Figure 4. The complete data set of travel-time anomalies for Pahute Mesa (top) and Yucca Flat (bottom).

other. However, the Pahute Mesa pattern is noticeably stronger. This suggests that although the two sub-sites have a strong common component in their travel-time variations, Pahute Mesa appears to have an additional travel-time variation.

In order to examine the azimuthal systematics of the magnitude and travel-time variations, we have calculated the station means for each data set. The station mean magnitude anomalies are plotted on equal-area projections in Fig. 5 for the two explosion sub-sites and the regional events. Here the similarity between the Pahute Mesa and Yucca Flat patterns is readily apparent. Both sites have low magnitudes to the $\mathrm{N}$ and NNE, and relatively high magnitudes to the $E$ and $W$. The most noticeable systematic differences between the sub-sites are at more distant stations to the NE, which have relatively lower magnitudes for Pahute Mesa, and at stations to the ENE, which have relatively lower magnitudes for Yucca Flat. Our purpose is to explain both the common variations and the intersite differences in these patterns.

The earthquake pattern (Fig. 5c) has some similarities to the explosion patterns, indicating that near-receiver effects do contribute to the latter. These effects may include impedance effects, attenuation differences or focusing near the receivers for this azimuth of approach. In order to test this, the station mean magnitude anomalies for Pahute Mesa and Yucca Flat are regressed against the station mean magnitude anomalies for the regional event data set (Fig. 6). The correlation coefficients of the regressions ( 0.506 for Pahute Mesa and 0.518 for Yucca Flat) are fairly high, suggesting that a common receiver component is 

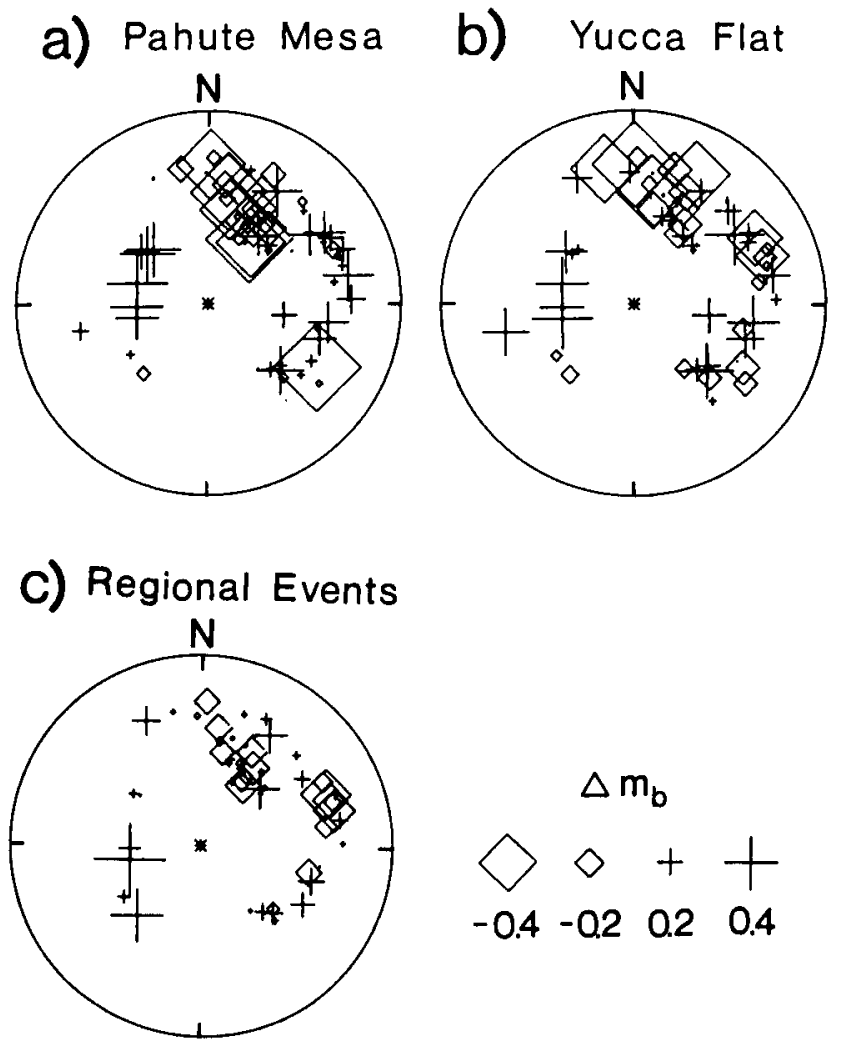

Figure 5. Station average magnitude anomalies for (a) Pahute Mesa, (b) Yucca Flat and (c) regional events, plotted on equal-area nets. The circumference corresponds to a take-off angle of $22.5^{\circ}$ in a source medium with a velocity of $3.5 \mathrm{~km} \mathrm{~s}^{-1}$.

present. These correlations basically represent the stationto-station variability in the magnitude anomalies. Thus, the regional event anomalies probably provide reasonably good first-order corrections for the near-receiver effects, although a larger data set would be desirable for computing more stable corrections. However, the station mean values in the earthquake data set are considerably smaller and less coherent with azimuth, implying that most of the signal common to Pahute Mesa and Yucca Flat arises from near-source effects.
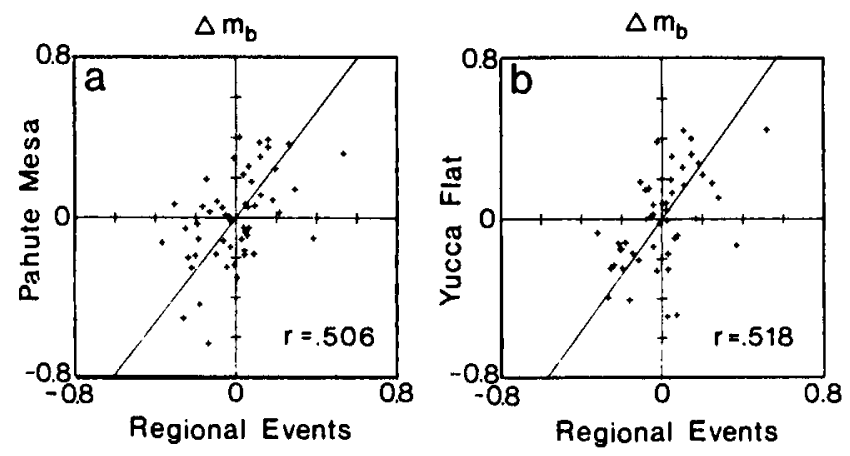

Figure 6. Major-axis regressions of station mean magnitude anomalies (without regional event station corrections) for (a) Pahute Mesa events vs. regional events and (b) Yucca Flat events vs. regional events. The linear correlation coefficient $(r)$ for each regression is shown in the lower right corner.
The station mean travel-time residuals for Pahute Mesa, Yucca Flat, and FAULTLESS are plotted in equal-area projections in the top row of Fig. 7. The station corrections of Dziewonski \& Anderson (1983), which have been added to the theoretical travel times in computing the anomalies, are shown in Fig. 7(d). As in the case of the magnitude variations, the Pahute Mesa and Yucca Flat patterns are remarkably similar, with Pahute Mesa having the stronger pattern. Both have fast travel times at stations to the NE and slow times at stations to the SE and NW. The travel time pattern for FAULTLESS is rather similar to the NTS patterns, suggesting that the three patterns have a common contribution on the order of 1-2s variation from deep-mantle or systematic receiver effects.

The station corrections do indicate a systematic receiver contribution, but with opposite sense to the travel-time residuals. Thus, some component of the travel-time patterns apparently results from the inclusion of these corrections in the travel-time residual calculations. Travel-time residuals calculated using simple elevation corrections, rather than the station corrections of Dziewonski \& Anderson (1983), are shown in the bottom row of Fig. 7. The station means retain the long-wavelength component of the pattern for Pahute Mesa and Yucca Flat, albeit somewhat reduced in magnitude and coherence. Given that Dziewonski \& Anderson's (1983) station corrections are the best available, and that their removal does not dramatically change the overall pattern for NTS, the results used in the rest of this paper will be those with the station corrections included unless otherwise noted. It is interesting to note, however, that the fundamental assumption that slowly-varying patterns are necessarily near-source effects is contradicted by the systematic pattern in the station corrections in Fig. 7(d).

The equal-area projections of station mean magnitude (Fig. 5) and travel-time anomalies (Fig. 7) show that stations to the NE tend to record fast travel times and low magnitudes, and stations to the $\mathrm{E}$ and $\mathrm{SE}$ tend to record slow travel times and high magnitudes. This positive correlation of anomalies indicates a focusing/defocusing effect rather than an attenuation effect, for which we would expect a negative correlation. Chang and von Seggern (1980) also observed a positive linear correlation between travel-time and magnitude anomalies at the LASA array, which they attributed to focusing and defocusing effects by local crustal velocity heterogeneity. A similar relationship was noted by Butler (1983) for $P$-wave travel time and log amplitude residuals for stations in western North America. The positive correlation for elastic focusing and defocusing is also typical of the studies tracing rays through high-velocity subducting slabs, where the times recorded in the shadow zone of the slab are generally fast (Sleep 1973).

In order to quantify this correlation, we regressed travel time vs. magnitude anomalies (Fig. 8). Since both the magnitudes (abscissa) and travel times (ordinate) are subject to error, we used the reduced major-axis regression, which scales each data set by its standard deviation and then minimizes the sum of the squared distances from $x-y$ pairs perpendicularly to the best-fit line (York 1966; Kermack \& Haldane 1950). We also calculate the linear correlation coefficient, $r$. The probability $P_{0}$ that the correlation coefficient would be greater than the observed value if there 



Figure 7. (a-c) Station average travel-time anomalies for Pahute Mesa events, Yucca Flat events, and FAULTLESS, computed using the azimuthally-dependent station corrections of Dziewonski and Anderson (1983). (d) The azimuthally-dependent station corrections of Dziewonski \& Anderson (1983). (e-g) Station average travel-time anomalies computed using only simple elevation corrections for Pahute Mesa, Yucca Flat and FAULTLESS, respectively.

were no correlation is computed as $\operatorname{erfc}\left(r^{2} N / 2\right)^{1 / 2}$, where $\operatorname{erfc}(x)$ is the complementary error function (Press $e t$ al. 1986). Stations that have less than three observations are excluded from this and all future statistical treatments of station means in this paper. Station BHP has also been removed because it has anomalously low magnitudes that are the result of obvious near-receiver multipathing.

The station mean travel-time anomalies, with the Dziewonski \& Anderson (1983) station corrections included, were regressed against the station mean magnitude anomalies with the earthquake station means subtracted as corrections (Fig. 8a, b). The correlation coefficient is 0.355 for Pahute Mesa events and 0.219 for Yucca Flat events, and the corresponding values of $P_{0}$ are 0.01 and 0.14 . Thus, the probability that the travel-time and magnitude anomalies would yield correlation coefficients as high as those observed if they were uncorrelated is quite small for Pahute Mesa events, but fairly high for Yucca Flat events. This suggests that the Pahute Mesa events show stronger near-source focusing/defocusing effects.

If the simple elevation corrections are applied to the travel times and the station magnitude corrections are not applied (Fig. 8c, d), the regressions for the station means give correlation coefficients of 0.385 for Pahute Mesa and 0.330 for Yucca Flat, with corresponding values for $P_{0}$ of 0.005 and 0.025 . Thus, both test sites show significant positive correlations when no station corrections are made. The higher correlation for anomalies that do not include station corrections suggests the presence of additional near-receiver focusing/defocusing effects, which are at least
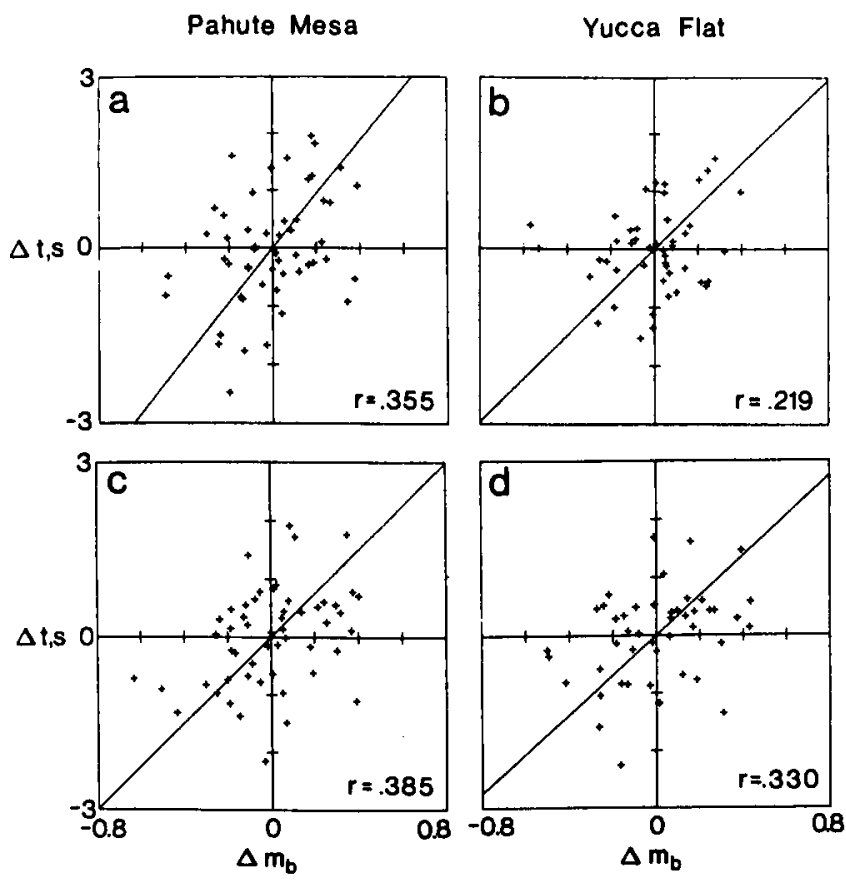

Figure 8. (a-b) Regressions of corresponding station mean travel-time anomalies vs. magnitude anomalies (including station corrections for both) for Pahute Mesa and Yucca Flat events, (c-d) Regression of station mean travel times with elevation corrections only against uncorrected station mean magnitude anomalies. The linear correlation coefficient $(r)$ for each regression is shown in the lower right corner. 
partially removed by the application of the station corrections.

It is not surprising that the above correlations are not high, since elastic focusing/defocusing does not necessarily produce a simple linear correlation between amplitudes and travel times (Cormier 1987), and attenuation effects, with an opposite sense of correlation, may further degrade the observed correlations. For example, travel-time and amplitude variations across North America from earthquake sources appear to be dominated by attenuation effects, which produce an overall negative correlation for the entire continent, while sub-regions indicate a preponderance of focusing/defocusing effects (Lay \& Helmberger, Butler 1983; Butler 1984).

The two NTS sub-sites show similar relationships between magnitude and travel-time anomalies (Fig. 8), and we have noted that the travel-time and magnitude patterns of the sites are similar (Figs. 5, 7). It is thus of interest to compare the two sites directly by regressing the station means of a given type of measurement for Yucca Flat events against the corresponding station means for Pahute Mesa events. The results for both magnitude and travel-time anomaly regressions are shown in Fig. 9. The regression of Yucca Flat vs. Pahute Mesa $m_{\mathrm{b}}$ anomalies, with receiver corrections, yields a linear correlation coefficient of 0.602 and a slope of $1.1 \pm 0.2$, substantiating the presence of a significant common component in the NTS magnitude patterns. The correlation coefficient without receiver

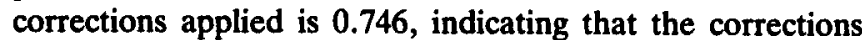
have removed some near-receiver component common to both test sites. The regression of Yucca Flat travel times against Pahute Mesa travel times yields a very high linear correlation coefficient of 0.965 and a slope of $0.87 \pm 0.03$. This is a strong indication of a common source for the primary characteristics of the travel-time patterns. However, the slope of the best-fit line is significantly less than unity, reflecting the additional strength of the Pahute Mesa travel-time pattern. If the elevation corrections are substituted for the Dziewonski \& Anderson (1983) station corrections, the correlation coefficient is 0.962 , but the slope is increased to $0.95 \pm 0.04$. The increase in slope may be a result of domination by receiver terms.

In order to isolate effects more likely to be generated close to the source regions, it is helpful to examine the slowly-varying components of the variations. We para-
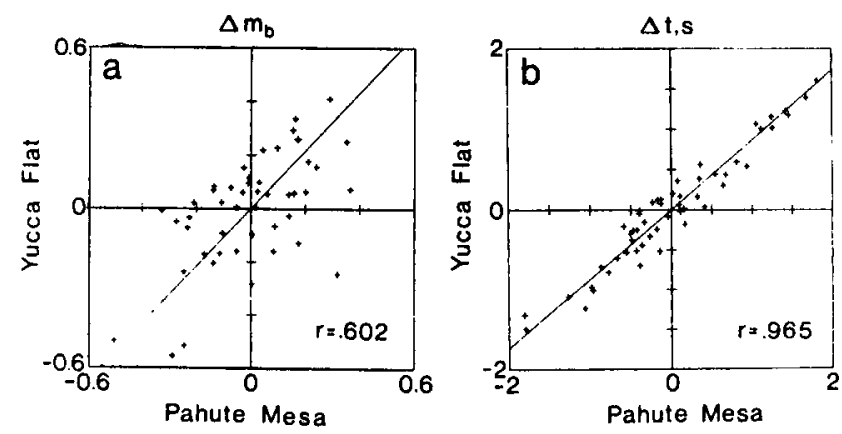

Figure 9. (a) Major-axis regression of station mean magnitude anomalies for Yucca Flat events vs. Pahute Mesa events. (b) Same as (a) for travel-time anomalies. The linear correlation coefficient ( $r$ ) for each regression is shown in the lower right corner.
Table 2. Sine curve regressions of the form $A_{0} \sin \left[n\left(\theta-\theta_{0}\right)\right]$.

\begin{tabular}{lrrrrr} 
Data Set & & \multicolumn{2}{c}{$\begin{array}{c}\text { lobe } \\
\text { azi. }\end{array}$} & $A_{0}$ & $F$ \\
\hline Pahute Mesa & $\mathrm{m}_{\mathrm{b}}$ & 2 & 10 & 0.20 & 16.5 \\
Yucca Flat & $\mathrm{m}_{\mathrm{b}}$ & 2 & 19 & 0.11 & 3.3 \\
Regional events & $\mathrm{m}_{\mathrm{b}}$ & 2 & 28 & 0.03 & 0.6 \\
$\mathrm{~m}_{\mathrm{b}}$ bias & $\mathrm{m}_{\mathrm{b}}$ & 2 & -10 & 0.02 & 0.5 \\
Pahute Mesa (corrected) & $\mathrm{m}_{\mathrm{b}}$ & 2 & 7 & 0.17 & 13.6 \\
Yucca Flat (corrected) & $\mathrm{m}_{\mathrm{b}}$ & 2 & 22 & 0.08 & 2.0 \\
Pahute Mesa & $\mathrm{t}$ & 2 & 36 & 0.71 & 16.3 \\
Yucca Flat & $\mathrm{t}$ & 2 & 31 & 0.52 & 11.7 \\
FAULTLESS & $\mathrm{t}$ & 2 & 61 & 0.66 & 7.1 \\
Pahute Mesa-Yucca Flat & $\mathrm{m}_{\mathrm{b}}$ & 2 & -1 & 0.06 & 2.0 \\
\hline Pahute Mesa-Yucca Flat & $\mathrm{m}_{\mathrm{b}}$ & 3 & 12 & 0.09 & 5.7 \\
Pahute Mesa-Yucca Flat & $\mathrm{t}$ & 2 & 40 & 0.18 & 13.4 \\
\hline Pahute Mesa-Yucca Flat & $\mathrm{t}$ & 3 & 39 & 0.20 & 11.8 \\
\hline
\end{tabular}

meterize these components by regressing a curve of the form $A_{0} \sin \left[2\left(\theta-\theta_{0}\right)\right]$, where $\theta$ is the azimuth to the station and $\theta_{0}$ is a phase shift term. This procedure is not motivated by a physical model of the causal process, but is simply intended to parameterize the dominant long-wavelength components of the travel-time and magnitude patterns. The amplitude $\left(A_{0}\right)$ and azimuth of the northerly negative lobe (Fig. 10) for each regression are listed in Table 2. The $F$-test was applied to ascertain whether a given regression significantly reduces the variance relative to the mean (Table 2).

On the left-hand side of Fig. 10, the station-averaged magnitude anomalies for Pahute Mesa, Yucca Flat and the regional event data set are plotted as functions of azimuth, along with corresponding $\sin 2 \theta$ curve regressions. The corresponding station means for the two explosion sites with station corrections applied (i.e., the station means for the regional events) are shown on the right in Fig. 10. In order to directly compare the patterns with and without corrections, only those stations for which a regional event station mean was obtained are shown in the figure. The $\sin 2 \theta$ curve for Yucca Flat is similar in phase to that for Pahute Mesa, with low magnitudes to the NNE, but its amplitude and $F$-value are much smaller. Application of the station corrections to the Pahute Mesa data produces little change in the $\sin 2 \theta$ pattern, and an $F$-value that is only slightly reduced. In fact, the azimuthal pattern appears even more coherent than in the uncorrected case for the $\mathrm{N}$ and $\mathrm{E}$ azimuths, where most of the stations lie, indicating that receiver-induced scatter has been reduced. The slight decrease in $F$-value appears to be due to the stations in the $\mathrm{W}$, for which the corrections are based on few events and show a great deal of scatter (Fig. 3). Application of the station corrections reduces the Yucca Flat $\sin 2 \theta$ pattern to the point where it fails the $F$-test at the 90 per cent 


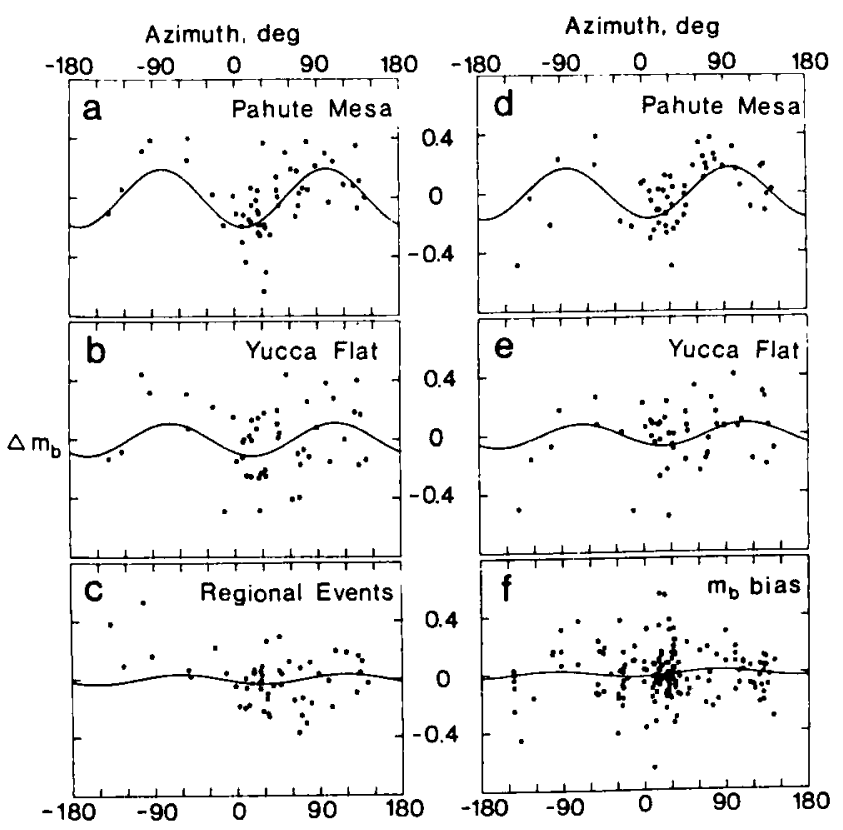

Figure 10. Regressions of $\sin 2 \theta$ curves on station average magnitude anomalies vs. azimuth for (a) Pahute Mesa, (b) Yucca Flat and (c) regional events. No station corrections have been applied, but only those stations that have values for the regional events are used in the regressions. (d-e) Same as $(a-b)$, but with regional event station corrections included. (f) $\operatorname{Sin} 2 \theta$ regression on $m_{\mathrm{b}}$ bias station terms from North (1977), Ringdal (1984) and Blandford et al. (1984).

confidence level. The Yucca Flat pattern is somewhat similar to that for Pahute Mesa except in the NNE, where Pahute Mesa has systematically lower $m_{\mathrm{b}}$ anomalies. Thus, there seems to be a small component common to both sub-sites, as suggested by the correlation of station $m_{\mathrm{b}}$ anomalies between sub-sites (Fig. 9). However, the principal long-wavelength variation in $m_{\mathrm{b}}$ is unique to Pahute Mesa.

The $\sin 2 \theta$ regression to the regional event station corrections themselves (Fig. 10c, Table 2) confirms that no significant long-wavelength pattern is present in the corrections. Given that the regional event station corrections comprise a relatively small number of data, we have also compiled the $m_{\mathrm{b}}$ bias values from North (1977), Ringdal (1984) and Blandford et al. (1984) for all stations in the teleseismic range from NTS and regressed a $\sin 2 \theta$ curve to these. This set of values includes stations used in this study as well as non-standard stations. When two or more values were available for a given station, both were used in the regression. The resulting regression (Fig. 10f, Table 2) corroborates the absence of any pervasive slowly-varying component in the station terms that would result from systematic attenuation or impedance variations at the receivers. Since the ray-paths from the regional events are similar to those from NTS at a given station, the long-wavelength variation that is seen in the Pahute Mesa station anomalies, and to some extent in the Yucca Flat station anomalies, is not a systematic receiver effect. Therefore, the small common component of these patterns must arise from propagation effects deep enough $(>200 \mathrm{~km})$ to affect both sub-sites similarly, while the remaining components must arise from shallower effects.
As with the magnitude anomalies, we characterize the slowly-varying component of the travel-time anomalies by $\sin 2 \theta$ azimuthal regressions (Table 2). The results for the station average travel-time anomalies for Pahute Mesa, Yucca Flat, and FAULTLESS are shown in Fig. 11. The regressions for the two NTS sites are significant at the 99 per cent level, and the regression for FAULTLESS is significant at the 95 per cent level. The pattern for Pahute Mesa has a higher amplitude than that for Yucca Flat. However, the long-wavelength components of both the Pahute Mesa and Yucca Flat travel-time patterns are rotated clockwise from the corresponding magnitude patterns $\left(26^{\circ}\right.$ and $12^{\circ}$, respectively). This systematic rotation must contribute to the low correlation coefficients in Fig. 8.

The $\sin 2 \theta$ regression for FAULTLESS bears some similarity to the regressions for the other two test sites, indicating that some of the variation is a deep-mantle effect (assuming that the receiver corrections are accurate). However, the FAULTLESS pattern is rotated clockwise $25^{\circ}-30^{\circ}$ relative to the other two travel-time patterns. In order to quantify the common trends in the travel-time patterns for the NTS sites and FAULTLESS, we have regressed the station mean anomalies for Pahute Mesa and

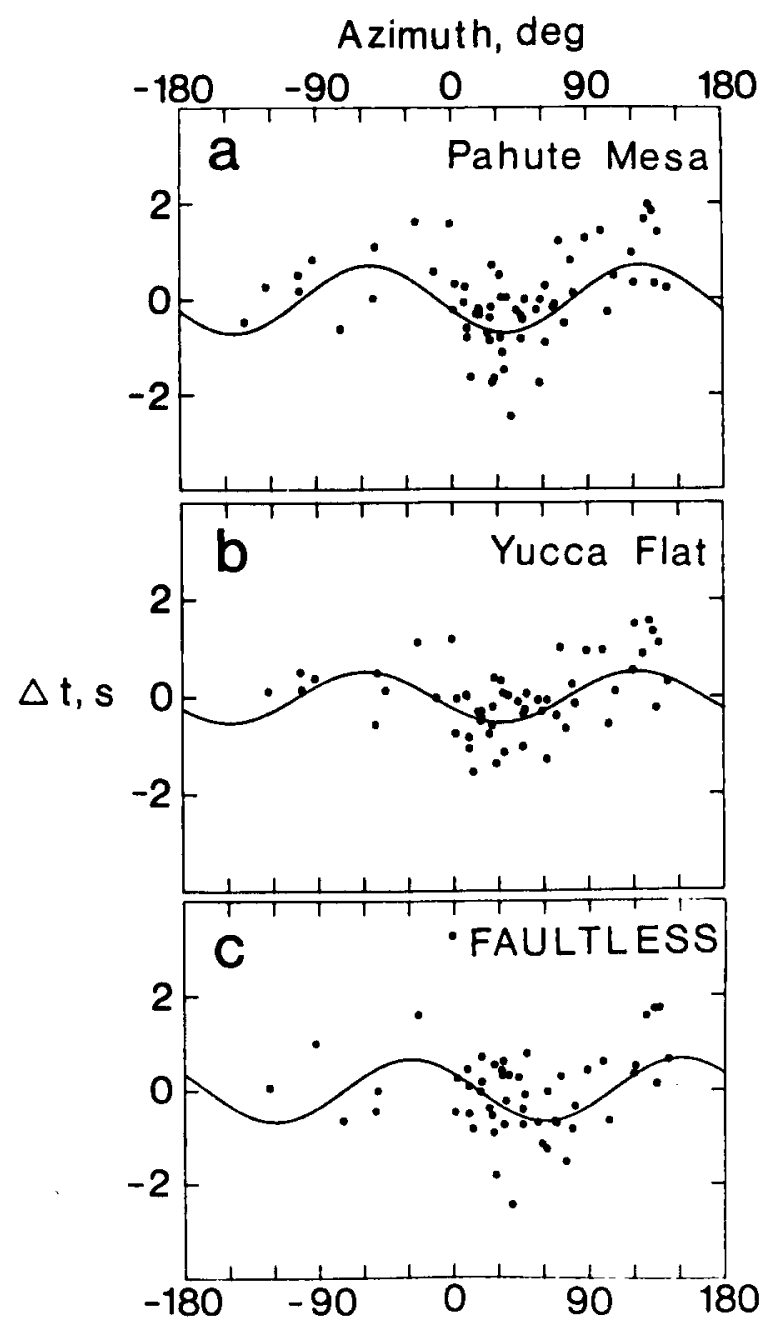

Figure 11. Regression of $\sin 2 \theta$ curves on station mean travel-time anomalies for (a) Pahute Mesa, (b) Yucca Flat and (c) FAULTLESS. 

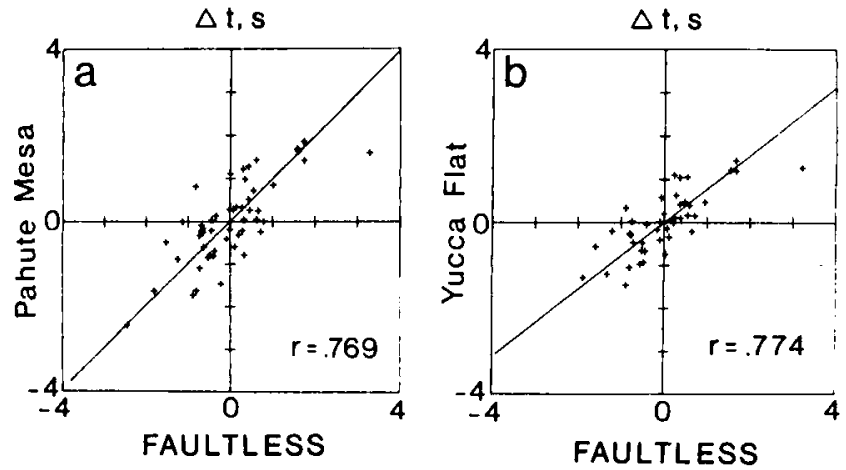

Figure 12. (a) Major-axis regressions of station mean travel-time anomalies for Pahute Mesa events vs. travel-time anomalies for FAULTLESS. (b) Same as (a) for Yucca Flat events vs. FAULTLESS. The linear correlation coefficient $(r)$ for each regression is shown in the lower right corner.

for Yucca Flat events against the travel-time anomalies for FAULTLESS (Fig. 12). The correlation coefficients are quite high (0.769 and 0.774 , respectively), implying that the velocity heterogeneity that affects both Pahute Mesa and Yucca Flat also contributes to the FAULTLESS travel-time pattern.

To ensure that this correlation does not simply stem from the common station corrections, we performed the same regressions using the travel-time anomalies calculated using only elevation corrections. The correlation coefficients for this case are even higher $(0.783$ for Pahute Mesa vs. FAULTLESS and 0.811 for Yucca Flat events vs. FAULTLESS), again suggesting that the influence of receiver contributions is partially reduced by applying the station corrections. A deep-mantle source for the common patterns seems most likely because the travel-time patterns for the different test sites have similar features whether or not station corrections are applied, and because the patterns are negatively correlated with the station corrections of Dziewonski \& Anderson (1983). In fact, if the NTS travel-time variations result from a high-velocity body to the northeast of NTS, the relative clockwise rotation of the FAULTLESS pattern could also be explained, since the high velocities (and relatively fast times) would be more easterly from FAULTLESS than from NTS. If this is the case, the heterogeneity must lie at depths greater than $400 \mathrm{~km}$.

While the slowly-varying components of the amplitude and travel-time patterns that are common to both sub-sites must originate at depths greater than $200 \mathrm{~km}$, shallower effects may explain the intersite differences in the patterns. Since Yucca Flat and Pahute Mesa are separated by only about $30 \mathrm{~km}$, we should be able to remove completely any common deep-mantle or receiver component by differencing the station means for Yucca Flat $\left({ }_{\mathrm{YF}} s_{i}\right)$ events from those for Pahute Mesa events $\left(\mathrm{PM}_{i} s_{i}\right)$, i.e. $\Delta s_{i}={ }_{\mathrm{PM}} s_{i}-{ }_{\mathrm{YF}} s_{i}$. The differences are adjusted to zero mean in order to identify the azimuthal variation. Both the differenced magnitude and travel-time patterns exhibit coherent, slowly-varying patterns similar to the overall patterns (Fig. 13). Again there is some visual correlation in the equal-area projections between relatively fast times and low magnitudes to the NE. To quantify this correlation, we have regressed the differenced travel times against the differenced magnitudes (Fig. 13c). The linear correlation coefficient is 0.347 , with a probability of no correlation $\left(P_{0}\right)$ of 0.012 . This correlation, together with the additional strength of the Pahute Mesa patterns, suggests a predominance of elastic focusing and defocusing effects in the crust and upper mantle beneath Pahute Mesa.

The slope of this regression is $1.3 \pm 0.5$, which is considerably reduced from the slopes found in the regression of the individual sites (Fig. 8). This is due to the fact that the differencing procedure has drastically reduced the size of the travel-time anomalies, while the magnitude anomalies have been reduced only slightly in size (Fig. 13). This may be an indication that the magnitude anomalies are not strongly affected by the deep-mantle heterogeneities

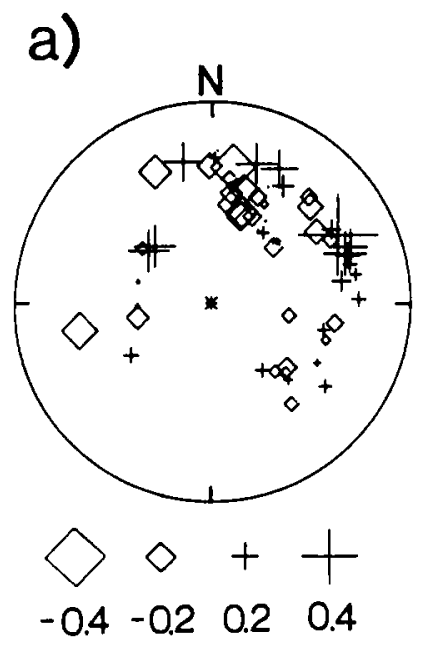

$\Delta m_{b}$ b)

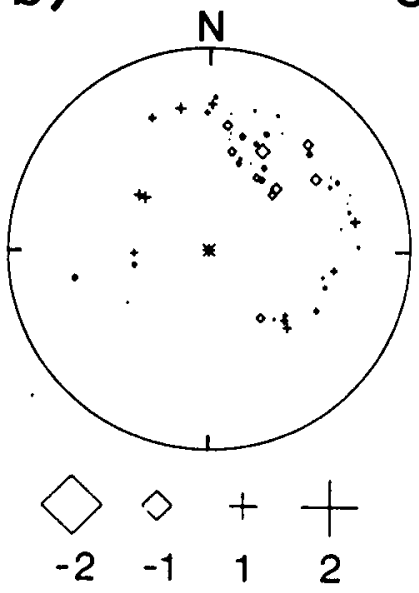

$\Delta t, s$ c)

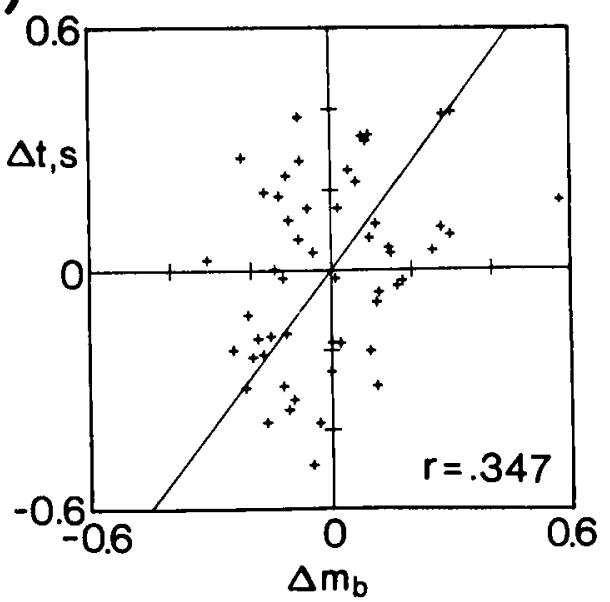

Figure 13. (a) Results of differencing station mean magnitude anomalies for Yucca Flat events from those for Pahute Mesa events. (b) Same as (a) for travel-time anomalies. (c) Major-axis regressions of differenced station mean travel-time anomalies vs. differenced magnitude anomalies. The linear correlation coefficient $(r)$ is shown in the lower right corner. 


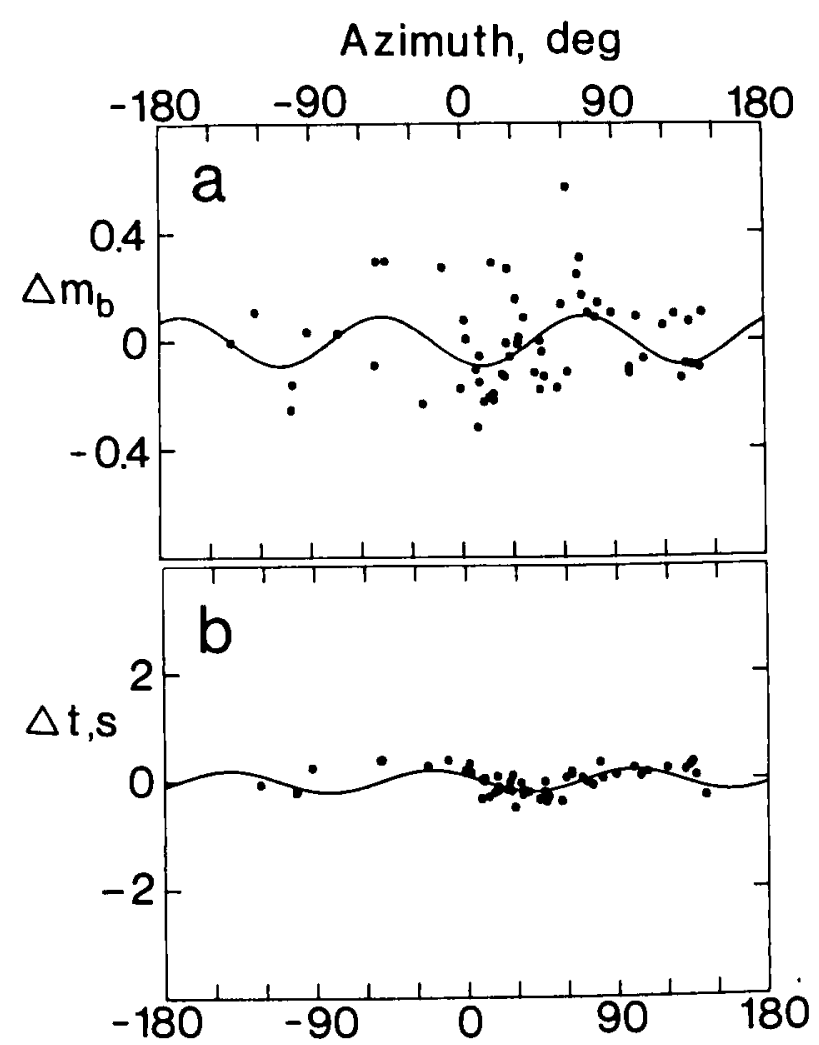

Figure 14. (a) Regressions of $\sin 3 \theta$ curves on differenced (Pahute Mesa-Yucca Flat) magnitude anomalies. (b) Same as (a) for travel-time anomalies.

that produce the principal travel-time anomalies. However, the differenced magnitude pattern does appear to have a somewhat shorter wavelength than the overall magnitude patterns: the $\sin 2 \theta$ fit for the differenced magnitudes fails the $F$-test at the 90 per cent level, but a $\sin 3 \theta$ fit passes the $F$-test at the 99 per cent confidence level (Fig. 14, Table 2).

The travel times pass the $F$-test at the 99 per cent level for either a $\sin 2 \theta$ or a $\sin 3 \theta$ parameterization. As with the patterns of the individual test sites (Figs. 10, 11), the long-wavelength component for the travel times is rotated somewhat clockwise from that for the magnitudes (Fig. 14), suggesting that the relationship between magnitude and travel-time anomalies near the source is not straightforward. This is not unexpected since travel times are sensitive to the history of velocities along the ray-path, while amplitudes are sensitive to the curvature (i.e. second derivative) of the velocity field. Thus, the amplitude field is also intrinsically more variable: small ray-path deflections that yield negligible travel-time deviations when they are incorporated may produce sizeable amplitude differences (Thomson 1983). It is important to be cognizant of this behaviour when appraising the correlations of amplitudes and travel times.

\section{DISCUSSION}

With the data collected in this study, we can rule out several possibilities for the source of the magnitude variations from Pahute Mesa explosions. We have shown for the first time that fast travel times have a weak but significant correlation with relatively low-magnitude measurements on a one-toone basis for the NTS explosions. Furthermore, the long-wavelength components of the travel-time patterns and the magnitude patterns exhibit similar behaviour. These correlations are not predicted by the tectonic release interference hypothesis (Lay et al. 1984); therefore, it appears that the latter model is not the best (or at least not a complete) explanation for the observations of non-isotropic short-period $P$-wave radiation from Pahute Mesa explosions.

This is corroborated by the results of Lay \& Welc (1987) who found no correlation between early $P$-coda complexity and tectonic release F-factor for Pahute Mesa and Yucca Flat explosions, and by Lay (1987) who found no correlation of $P$-coda dispersion with $F$-factor. While it appears that tectonic release has little effect on the short-period $P$-waves, we have not absolutely ruled out tectonic release effects in all cases.

The sense of the travel-time/amplitude correlation is also important, since it favours the interpretation that the magnitude patterns result principally from focusing and defocusing by laterally varying velocity structure. It is difficult to formulate a model of anelastic heterogeneity that predicts systematically low amplitudes correlating with fast velocities.

The superposition of several propagation effects on both the travel-time and magnitude patterns for the NTS events makes the isolation of the near-source components difficult. The application of the regional earthquakes as station corrections appears to have had some success in improving the coherence of the long-wavelength variation in magnitudes for Pahute Mesa. However, it degraded the corresponding pattern for Yucca Flat, suggesting that a significant part of the latter pattern is due to systematic near-receiver effects. Thus, the principal long-wavelength variation seems to be unique to Pahute Mesa. The strong intersite differences in $m_{\mathrm{b}}$ and travel times indicate velocity heterogeneity that is shallow enough to affect the sub-sites differently $(<200 \mathrm{~km})$. Also, the heterogeneity must be deeper than the Pahute Mesa source array is wide (about $30 \mathrm{~km}$ ) in order to affect each explosion in the sub-site similarly, as indicated by the small scatter about the station means (Fig. 3). In addition, deep heterogeneity $(>200 \mathrm{~km})$ may be producing a small common component in the NTS $m_{\mathrm{b}}$ patterns.

For the travel times, a well-constrained set of azimuthally-dependent receiver corrections does exist (Dziewonski \& Anderson 1983), but it is difficult to tell how useful they are for NTS sources. The negative correlation between travel-time anomalies and the station corrections applied demonstrates that some of the power of the anomaly pattern results from the application of the corrections themselves. Whether the corrections are applied or not, however, the strong correlation between the Yucca Flat and Pahute Mesa travel times is suggestive of a strong common component resulting from deep-mantle structure. These travel-time anomalies also bear similarities to the FAULTLESS travel-time pattern, suggesting that they result from the same deep $(>400 \mathrm{~km})$ mantle structure. There is a good correlation of the travel time anomalies for relatively close stations with the upper mantle $P$-wave velocity structure under the United States obtained by 
Romanowicz (1979). This model has relatively fast velocities in the lowermost layer $(450-700 \mathrm{~km})$ to the northeast of NTS.

The difference in azimuthal travel-time variation between Pahute Mesa and Yucca Flat (Figs. 13, 14), which reflects a near-source contribution, is similar to the overall travel-time patterns, albeit with much less range of variation $(0.4 \mathrm{~s})$. It is this relative accentuation of the Pahute Mesa azimuthal travel-time variation that gives rise to the high-velocity anomalies in the upper mantle NE of the mesa that were obtained in the 3-D travel-time inversions (Taylor 1983; Minster et al. 1981), which incorporate a similar differencing operation. These azimuthal differences are superimposed on a baseline shift of about $-0.3 \mathrm{~s}$ between Pahute Mesa and Yucca Flat resulting from different average crustal structure, so that the true azimuthal differences vary from -0.5 to $-0.1 \mathrm{~s}$. The crustal differences appear to be related to the localized high-velocity anomaly in the upper mantle, possibly as a continuous root (Spence, 1974; Minster et al. 1981; Taylor 1983).

Although the near-source magnitude pattern also has a long-wavelength component, the correlation with the travel times is only moderate, possibly due to the intrinsically non-linear relationship between amplitudes and travel times. However, 3-D models for the upper $200 \mathrm{~km}$ that are compatible with both the travel-time and amplitude variations do exist. Cormier (1987) computed amplitudes by tracing rays through Taylor's (1983) structure derived from travel-time variations and found an azimuthal pattern similar to the differenced magnitude pattern presented in this paper. Lynnes \& Lay (1987) inverted the intersite amplitude differences using the thin lens technique of Haddon \& Husebye (1978) to derive a warped velocity discontinuity at $160 \mathrm{~km}$ depth that qualitatively predicts the travel-time variations as well.

\section{CONCLUSION}

We have collected a comprehensive set of short-period $P$-wave travel-time and magnitude anomalies from 58 NTS explosions, together with magnitude anomalies from several regional earthquakes. A substantial slowly-varying pattern is found in the magnitude anomalies from Pahute Mesa explosions, with a similar but subdued pattern for Yucca Flat events after corrections for receiver effects. This pattern is characterized by low magnitudes recorded at stations to the $\mathrm{N}$ and $\mathrm{NE}$ of the test site. A similar azimuthal variation is found for the travel-time anomalies with a variation of $1.0-1.4 \mathrm{~s}$, but the correlation between test sites is so strong that a deep-mantle or near-receiver source probably produces the overall travel-time pattern. A negative correlation with the receiver corrections of Dziewonski \& Anderson (1983) suggests that a deep-mantle source is more likely.

By differencing the Yucca Flat station average-magnitude and travel-time anomalies from the corresponding Pahute Mesa measurements, we have isolated a slowly-varying near-source component. This is greatly reduced in power from the overall patterns for the travel times but constitutes much of the long-wavelength variation in the magnitudes. The existence of this near-source variation of magnitudes can clearly be a source of significant bias in small-network or single-array magnitude estimates. The overall travel-time anomalies correlate significantly and positively with the amplitude anomalies, suggesting the predominance of elastic focusing/defocusing effects, rather than variable attenuation or contamination by tectonic release. The differenced magnitude and travel-time patterns also correlate positively, suggesting an effect of shallow velocity heterogeneity in the uppermost mantle beneath the NTS source region. The general coherence of the travel-time and magnitude patterns found in this study and the travel time/magnitude correlation suggest that deterministic models can explain at least part of the observed short-period $P$-wave behaviour.

\section{ACKNOWLEDGMENTS}

Much of the data was collected at the Lamont-Doherty Geological Observatory WWSSN and CSN filmchip archives, which we gratefully acknowledge. We thank $R$. Blandford, S. Grand, W. Spence and an anonymous reviewer for helpful suggestions, and S. Schwartz and S. Beck for critically reading the manuscript. We also thank L. Ruff for providing a subroutine for the least-squares adjustment of relative source sizes. This research was supported by grants from the Exxon Foundation, the Michigan Memorial Phoenix Project and the Defense Advanced Research Projects Agency, and was monitored by the Air Force Geophysics Laboratory under Contract F19628-85-K-0030.

\section{REFERENCES}

Aki, K., 1973. Scattering of $P$ waves under the Montana Lasa, $J$. geophys. Res., 78, 1334-1346.

Bache, T. C., Lambert, D. G. \& Barker, T. G., 1980. A source model for the March 28, 1975 Pocatello Valley earthquake from time-domain modeling of teleseismic $P$ waves, Bull. seism. Soc. Am., 70, 405-418.

Berteussen, K. A., 1975. $P$ wave amplitude variability at NORSAR, J. Geophys., 41, 595-613.

Blandford, R. R., Shumway, R. H., Wagner, R. \& McLaughlin, K. L., 1984. Magnitude yield for nuclear explosions at several test sites with allowance for effects of truncated data, amplitude correlation between events within test sites, absorption, and pP, Technical Report TGAL-TR-83-6, Teledyne Geotech, Alexandria, Virginia.

Burdick, L. J. \& Helmberger, D. V., 1978. The upper mantle $P$ velocity structure of the western United States, J. geophys. Res., 83, 1699-1712.

Burger, R. W., Lay, T. \& Burdick, L. J., 1986. Estimating the relative yields of Novaya Zemlya tests by waveform intercorrelation, Geophys. J. R. astr. Soc., 87, 775-800.

Butler, R., 1983. $P$-wave travel time and amplitude in western North America, Nature, 306, 677-678.

Butler, R., 1984. Azimuth, energy, $Q$, and temperature: variations on $P$ wave amplitudes in the United States, Rev. Geophys. space Phys., 22, 1-36.

Butler, R. \& Ruff, L., 1980. Teleseismic short-period amplitudes: source and receiver variations, Bull. seism. Soc. Am., 70, 831-850.

Chang, A. C. \& von Seggern, D. H., 1980. A study of amplitude anomaly and $m_{\mathrm{b}}$ bias at LASA subarrays, J. geophys. Res., 85, 4811-4828.

Cormier, V. F., 1987. Focusing and defocusing of teleseismic $P$ waves by known 3-D structure beneath Pahute Mesa, Nevada Test Site, Bull. seism. Soc. Am., 77, 1688-1703.

Creager, K. C. \& Jordan, T. H., 1984. Slab penetration into the lower mantle, J. geophys. Res., 89, 3031-3049.

Davies, D. \& Julian, B., 1972. A study of short-period $P$-wave signals from Longshot, Geophys. J. R. astr. Soc., 29, 185-202. 
Dziewonski, A. M., 1984. Mapping the lower mantle: determination of lateral heterogeneity in $P$ velocity up to degree and order 6, J. geophys. Res., 89, 5929-5952.

Dziewonski, A. M. \& Anderson, D. L., 1981. Preliminary reference Earth model, Phys. Earth planet. Int., 25, 297-356.

Dziewonski, A. M. \& Anderson, D. L., 1983. Travel times and station corrections for $P$ waves at teleseismic distances, $J$. geophys. Res., 88, 3295-3314.

Dziewonski, A. M. \& Gilbert, F., 1976. The effect of small, aspherical perturbations on travel times and a re-examination of the corrections for ellipticity, Geophys. J. R. astr. Soc., 44, 7-17.

Ekstrom, G. \& Dziewonski, A. M., 1985. Centroid-moment tensor solutions for 35 earthquakes in western North America (1977-1983), Bull. seism. Soc. Am., 75, 23-39.

Ellsworth, W. L., Campbell, R. H., Hill, D. P., Page, R. A., Alewine, R. W., Hanks, T. C., Heaton, T. H., Hileman, J. A., Kanamori, H., Minster, B. \& Whitcomb, J. H., 1973. Point Mugu, California, earthquake of 21 February 1973 and its aftershocks, Science, 182, 1127-1129.

Haddon, R. A. W. \& Husebye, E. S., 1978. Joint interpretation of $P$ wave time and amplitude anomalies in terms of lithospheric heterogeneities, Geophys. J. R. astr. Soc., 55, 19-43.

Hartzell, S. H., Burdick, L. J. \& Lay, T., 1983. Effective source functions for Pahute Mesa nuclear tests, Final Report WCCP-R-83-3, Woodward Clyde Consultants, Pasadena, California.

Kermack, K. A. \& Haldane, J. B. S., 1950. Organic correlation and allometry, Biometrika, 37, 30-41.

Langston, C. A., 1978. The February 9, 1971 San Fernando earthquake: a study of source finiteness in teleseismic body waves, Bull. seism. Soc. Am., 68, 1-29.

Langston, C. A. \& Blum, D. E., 1977. The April 29, 1965, Puget Sound earthquake and the crustal and upper mantle structure of western Washington, Bull. seism. Soc. Am., 67, 693-711.

Langston, C. A. \& Butler, R., 1976. Focal mechanism of the August 1, 1975 Oroville earthquake, Bull. seism. Soc. Am., 66, 1111-1120.

Lay, T., 1987. Analysis of near-source contributions to early $P$ coda: 2. Frequency dependence, Bull. seism. Soc. Am., 77, $1252-1273$.

Lay, T. \& Helmberger, D. V., 1983. Body-wave amplitude and travel-time correlations across North America, Bull. seism. Soc. Am., 73, 1063-1076.

Lay, T., Wallace, T. C. \& Helmberger, D. V., 1984. The effects of tectonic release on short-period $P$ waves from NTS explosions, Bull. seism. Soc. Am., 74, 819-842.

Lay, T. \& Welc, J. L., 1987. Analysis of near-source contributions to early $P$ wave coda for underground explosions: 1 . waveform complexity, Bull. seism. Soc. Am., 77, 1017-1040.

Lynnes, C. S. \& Lay, T., 1988. Effect of near-source structure on short-period teleseismic $P$ wave amplitudes, in Scattering and
Attenuation of Seismic Waves, special issue of Pure and Applied Geophysics, in press.

Minster, J. B., Savino, J. M., Rodi, W. L., Jordan, T. H. \& Masso, J. F., 1981. Three-dimensional velocity structure of the crust and upper mantle beneath the Nevada test site. Final Technical Report SSS-R-81-5138, Science, Systems and Software, La Jolla, California.

North, R. G., 1977. Station magnitude bias-its determination, causes and effects. Technical Note 1977-24, Massachusetts Institute of Technology Lincoln Laboratory, Lexington, Massachusetts.

Press, W. H., Flannery, B. P., Teukolsky, S. A. \& Vetterling, W. T., 1986. Numerical Recipes, Cambridge University Press, London.

Ringdal, F., 1984. Study of magnitudes, seismicity and earthquake detectability using a global network, Technical Report C84-01, Center for Seismic Studies, Arlington, Virginia.

Romanowicz, B. A., 1979. Structure of the upper mantle beneath the United States by three-dimensional inversion of body wave arrival times, Geophys. J. R. astr. Soc., 57, 479-506.

Sleep, N. H., 1973. Teleseismic $P$ wave transmission through slabs, Bull. seism. Soc. Am., 63, 1349-1373.

Spence, W., 1974. $P$ wave residual differences and inferences on an upper mantle source for the Silent Canyon volcanic centre, Southern Great Basin, Nevada, Geophys. J. R. astr. Soc., 38, 505-523.

Taylor, S. R., 1983. Three-dimensional crust and upper mantle structure at the Nevada Test Site, J. geophys. Res., 88, $2220-2232$.

Thomson, C., 1983. Ray-theoretical amplitude inversion for laterally varying velocity structure below NORSAR, Geophys. $J$. R. astr. Soc., 74, 525-558.

Thomson, C. J. \& Gubbins, D., 1982. Three-dimensional lithospheric modelling at NORSAR: linearity of the method and amplitude variations from the anomalies, Geophys. J. $R$. astr. Soc., 71, 1-36.

Veith, K. F. \& Clawson, G. E., 1972. Magnitude from short-period $P$ wave data, Bull. seism. Soc. Am., 62, 435-452.

Wallace, T. C., Helmberger, D. V. \& Ebel, J. E., 1981. A broadband study of the 13 August 1978 Santa Barbara earthquake, Bull. seism. Soc. Am., 71, 1701-1718.

Wallace, T. C., Helmberger, D. V. \& Engen, G. R., 1983. Evidence of tectonic release from underground nuclear explosions in long-period $P$ waves, Bull. seism. Soc. Am., 73, 593-613.

Wallace, T. C., Helmberger, D. V. \& Engen, G. R., 1984. Evidence of tectonic release from underground nuclear explosions in long-period $S$ waves, Bull. seism. Soc. Am., 75, 157-174.

York, D., 1966. Least-squares fitting of a straight line, Can. J. Phys., 44, 1079-1086. 